\title{
Perancangan Aplikasi Penjadwalan Mata Kuliah Di Fakultas Ilmu Komputer Universitas Katolik Santo Thomas
}

\author{
Andy Paul Harianja ${ }^{1}$, Rolas Meiputra Nababan ${ }^{2}$ \\ ${ }^{1,2}$ Universitas Katolik Santo Thomas Medan, Jl. Setiabudi No. 479 F Tanjungsari, Medan, Indonesia
}

\section{ARTICLE INFORMATION}

Received: September, 27, 2020

Revised: September, 30, 2020

Available online: Oktober,31 2020

KEYWORDS

\begin{tabular}{l} 
ALGORITMA GENETIKA, PENJADWALAN \\
MATAKULIAH \\
\hline Phone: +62 812-1030-2907 \\
E-mail:apharianja@ gmail.com \\
rolasnababan12@gmail.com
\end{tabular}

\section{A $\quad \mathbf{B} \quad \mathbf{S}$ T $\mathbf{R}$ A $\mathbf{K}$}

Penelitian ini dilakukan untuk memperoleh jadwal mata kuliah pada Fakultas Ilmu Komputer Universitas Katolik Santo Thomas yang optimal, sehingga jumlah mata kuliah yang bentrok dapat dikurangi, beban mahasiswa lebih merata, serta penggunaan ruang kelas lebih optimal. Hal ini dilakukan dengan optimasi yaitu melalui penentuan jadwal mata kuliah. Optimasi jadwal dilakukan dengan menggunakan algoritma genetika. Algoritma genetika adalah salah satu algoritma yang tepat digunakan untuk memecahkan permasalahan dalam skala besar dan memiliki tingkat kompleksitas yang tinggi sehingga cocok untuk digunakan memecahkan masalah penjadwalan mata kuliah pada perguruan tinggi yang terkenal rumit dan memiliki banyak sekali variabel kendala yang harus dipenuhi dalam pembuatan jadwal yang baik. Hasil yang diharapkan dari penelitian ini adalah sebuah jadwal mata kuliah yang optima berdasarkan jumlah mata kuliah yang bentrok, beban mahasiswa, dan penggunaan ruang kelas. Setelah penelitian dilakukan diperoleh jadwal baru yang optimal.

\section{PENDAHULUAN}

Pengaturan waktu terhadap suatu kegiatan merupakan hal yang penting dilakukan agar kegiatan tersebut berlangsung secara lancar. Pengaturan waktu tersebut biasa disebut penjadwalan. Penyusunan jadwal kegiatan berkaitan dengan berbagai batasan/kendala yang harus dipenuhi sehingga memerlukan banyak pertimbangan untuk mendukung kegiatan tersebut.Sebagian besar kasus penentuan jadwal yang bisa diterapkan sangat sulit dicapai karena terkadang sumber daya waktu, tempat, orang, tidak sesuai dengan kebutuhan. Metode yang digunakan untuk menyelesaikan masalah penjadwalan ini adalah menggunakan pendekatan algoritma genetika[1]. Beberapa Hal yang perlu dipertimbangkan untuk menyusun jadwal (dalam hal ini mata kuliah) adalah dosen, ruang,mata kuliah, jam, dan hari. Algoritma genetika merupakan pendekatan komputasional untuk menyelesaikan masalah yang dimodelkan dengan proses biologi dari evolusi. Algoritma ini biasa digunakan untuk proses optimasi dan pencarian hasil yang terbaik [2], [3].

Penjadwalan mata kuliah di fakultas ilmu komputer mengunakan algortima Genetika sebagai metode utamanya. Penelitian tersebut diimplementasikan ke dalan sistem berbasis Web. Penelitian tersebut dilatar belakangi karena setiap semester Fakultas Ilmu Komputer Universitas Katolik Santo Thomas akan menyusun jadwal perkuliahan yang akan di laksanakan selama semester tersebut berlangung. Jadwal perkuliahan ini biasanya di susun oleh Wakil Dekan FIKOM dengan mengunakan Microsoft Excel [4]. Proses yang berlangsung selama ini yaitu Kepala Program Studi (kaprodi) akan meminta waktu kesediaan dosen kepada dosen FIKOM, kemudian Kapodi menyerahkannya kepada Wakil Dekan, dan kemudian Wakil Dekan akan menyusun jadwal perkuliahaan di Microsoft Excel.

Algoritma Genetika merupakan suatu metode optimasi untuk mencari solusi yang optimal dari suatu permasalahan. Algoritma Genetika banyak digunakan untuk mencari solusi masalah optimasi penjadwalan. Penjadwalan yang umumnya bersifat kompleks tidak mengijinkan sisi otak manusia untuk mencarikan solusi yang optimal dengan mudah. Dengan Algoritma Genetika, hal-hal yang perlu dihindarkan dalam pembuatan jadwal bisa dihilangkan, dan semua bentuk solusi yang menguntungkan pihak-pihak yang terkait akan lebih mudah untuk didapatkan. Algoritma Genetika mempunyai metodologi optimasi sederhana sebagai berikut [5]: 1). Menentukan populasi solusi sejumlah tertentu; 2). Menghitung nilai fitnes function semua solusi yang ada di dalam populasi; 3) Memilih beberapa solusi dengan nilai fitnes function yang paling tinggi; 40. Melakukan optimasi dengan cara mutasi dan crossover sebanyak yang diperlukan; 5). Menentukan solusi terbaik sebagai solusi terhadap permasalahan yang dioptimasi

Dalam menerapkan Algoritma Genetika untuk memecahkan masalah optimasi, perlu dilakukan analisa terhadap permasalahan yang akan dicarikan solusinya. Dalam menganalisa permasalahan, ada dua istilah yang muncul 1). Hard Constraint: yang merupakan batasan yang ada dalam permasalahan yang akan dicarikan solusi, yang tidak boleh dilanggar sama sekali. Solusi yang akan menjadi bagian dari populasi, adalah solusi yang tidak melanggar Hard Constraint ini; 2). Soft Constraint: yang merupakan batasan yang ada dalam permasalahan yang akan dicarikan solusi, tetapi dalam pencarian solusi, batasan ini masih bisa dilanggar.

Perancangan Aplikasi Penjadwalan Mata Kuliah Di Fakultas Ilmu Komputer Universitas Katolik Santo Thomas. 
Dan rumusan masalah dari peneliti sebelumnya dimana hanya kurikulum KKNI saja yang bisa di buat jadwalnya di dalam sistem. Jadi saat ini peniliti ingin mengembangkan sistem yang telah di buat sebelumnya, sehingga mata kuliah kurikulum lama \& KKNI bisa terdaftar dalam sistem. Dengan adanya permasalahan yang terjadi diatas, maka penulis bermaksud mengangkat Judul tentang Perancangan Aplikasi Penjadwalan Mata Kuliah di Fakultas Ilmu Komputer Universitas Katolik Santo Thomas. Tujuan dalam mengambil judul ini adalah untuk mempermudah Dosen Fakultas Ilmu Komputer Universitas Katolik Santo Thomas dalam membuat jadwal perkuliahaan [6].

\section{METODE PENELITIAN}

Dalam menyelesaikan sebuah penelitian perlu membuat sebuah langkah dan tahapan agar penelitian tersebut sesuai dengan kebutuhan dan selesai dengan waktu yang sudah ditentukan, adapun metodologi penelitian yang dilakukan dalam penelitian ini adalah [7]:

1. Perumusan ide-ide topik penelitian dan mengidentifikasi permasalahan.

2. Studi literatur dasar teori penelitia

3. Berdasarkan identifikasi masalah dan studi literatur teori, dapat dirumuskan masalah dalam penelitian ini, yaitu perlu dilakukannya optimasi jadwal mata kuliah pada Fakultas Ilmu Komputer Universitas Katolik Santo Thomas.

4. Dalam melakukan penelitian ini, data yang dibutuhkan adalah data ruangan-ruangan kelas yang tersedia serta kapasitas masing-masing ruangan untuk tempat kegiatan perkuliahan berlangsung. Dari ruangan- ruangan yang tersedia tersebut akan dicari mata kuliah yang kapasitasnya sesuai sehingga tidak terjadi kelebihan kapasitas. Selain itu, untuk dapat menentukan jadwal mata kuliah agar tidak bentrok, maka dibutuhkan juga nama dosen beserta nama mata kuliah yang diajarnya dan ditujukan untuk semester berapa mata kuliah tersebut diajarkan.

5. Merancang pembuatan aplikasi Model Penjadwalan Matakuliah.

6. Mengimplementasikan rancangan sistem dengan cara membangun serta membuat Perancangan Aplikasi Penjadwalan Mata Kuliah Pada Fakultas Ilmu Komputer Universitas Katolik Santo Thomas.

7. Menguji perangkat lunak yang sudah dibuat kemudian menganalisa hasil output apakah sudah sesuai tujuan yang sudah dirumuskan \& optimal.

\subsection{Perancangan}

\section{HASIL DAN PEMBAHASAN}

Berdasarkan gambar 1 menjelaskan bahwa pada sistem yang dibangun tersebut terdapat 2 aktor yaitu: admin, ka prodi/operator. Berikut ini penjelasan dari tugas masing-masing actor [7], [8].

1. Admin

Admin pertama melakukan login terlebih dahulu, agar admin masuk ke dashboard admin dan dapat mengelola penjadwalan matakuliah, di mulai dari mengelola data dosen, hari, matakuliah, ruang, jam dan lainnya

2. Kepala Prodi/Operator

Kepala Prodi terlebih dahulu melakukan login setelah itu dosen masuk ke halaman dashboard Kepala Prodi dan dapat memanupulasi data Kepala Prodi dan menetukan waktu tersedia, mengelola data dan melihat serta mencetak jadwal perkuliahan.

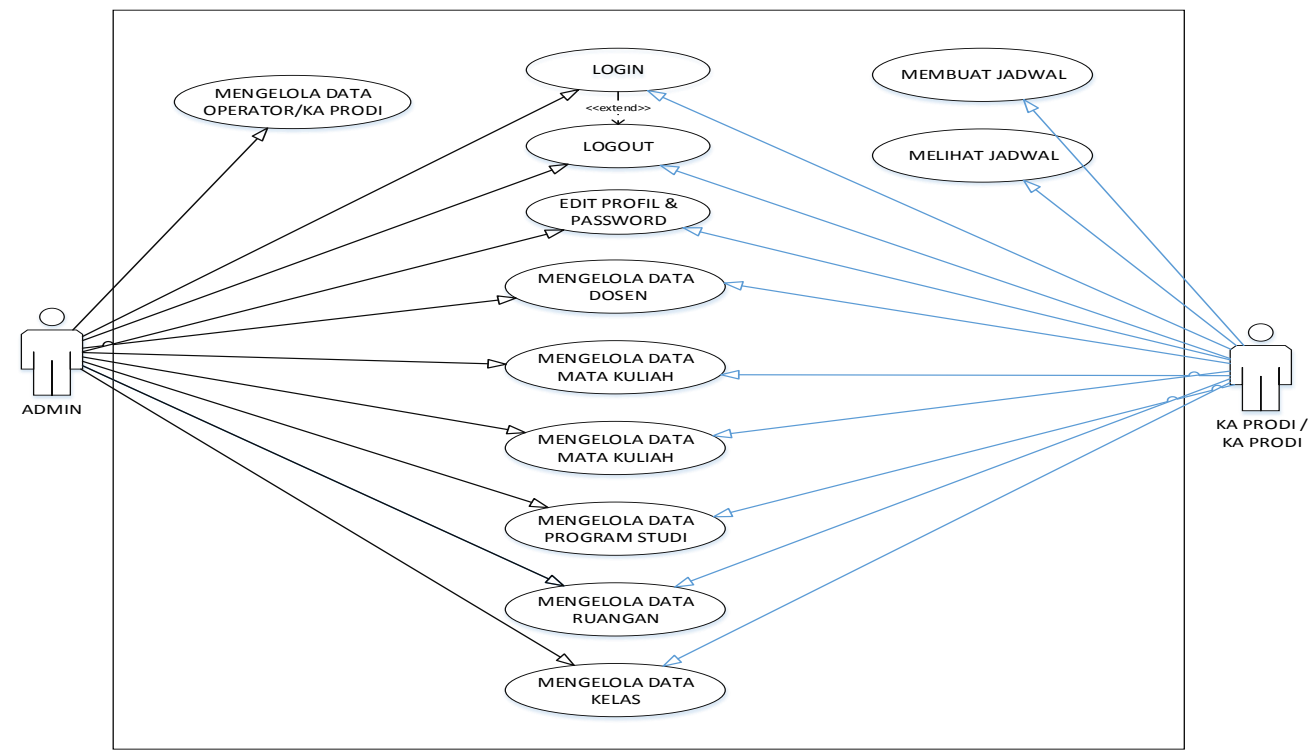

Gambar 1. Use Case Diagram Sistem Penjadwalan Mata Kuliah

Perancangan Aplikasi Penjadwalan Mata Kuliah Di Fakultas Ilmu Komputer Universitas Katolik Santo Thomas. 


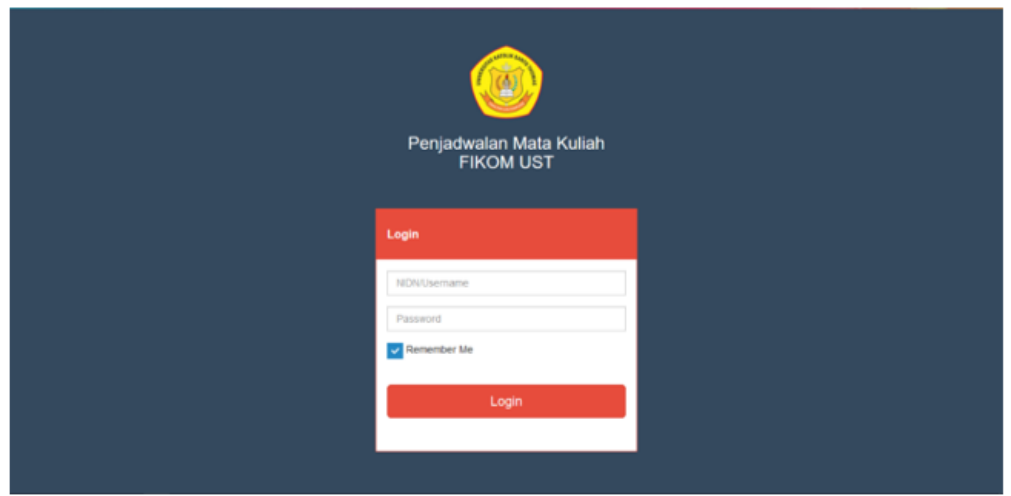

Gambar 2. Halaman Login

Gambar 2 berikut adalah tampilan antar muka menu login. Form login akan muncul ketika program pertama kali dijalankan. Menu ini berisi username dan password yang harus diisi agar dapat login ke sistem.

Gambar 3 berikut adalah tampilan antar muka menu dashboard. Menu ini dapat di akses admin dan operator/ka prodi setelah login terlebih dahulu.

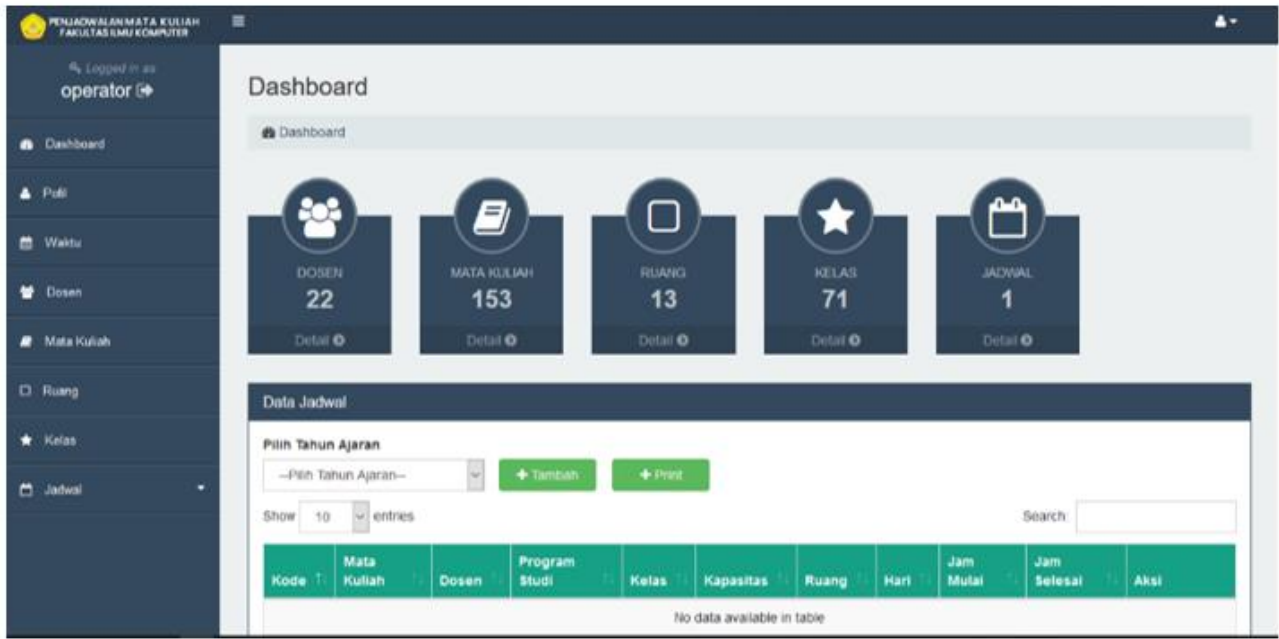

Gambar 3. Halaman Dashboard

Gambar 4 berikut adalah tampilan antar muka menu waktu. Form ini memiliki fitur yaitu Tambah data waktu, edit waktu dan hapus waktu.

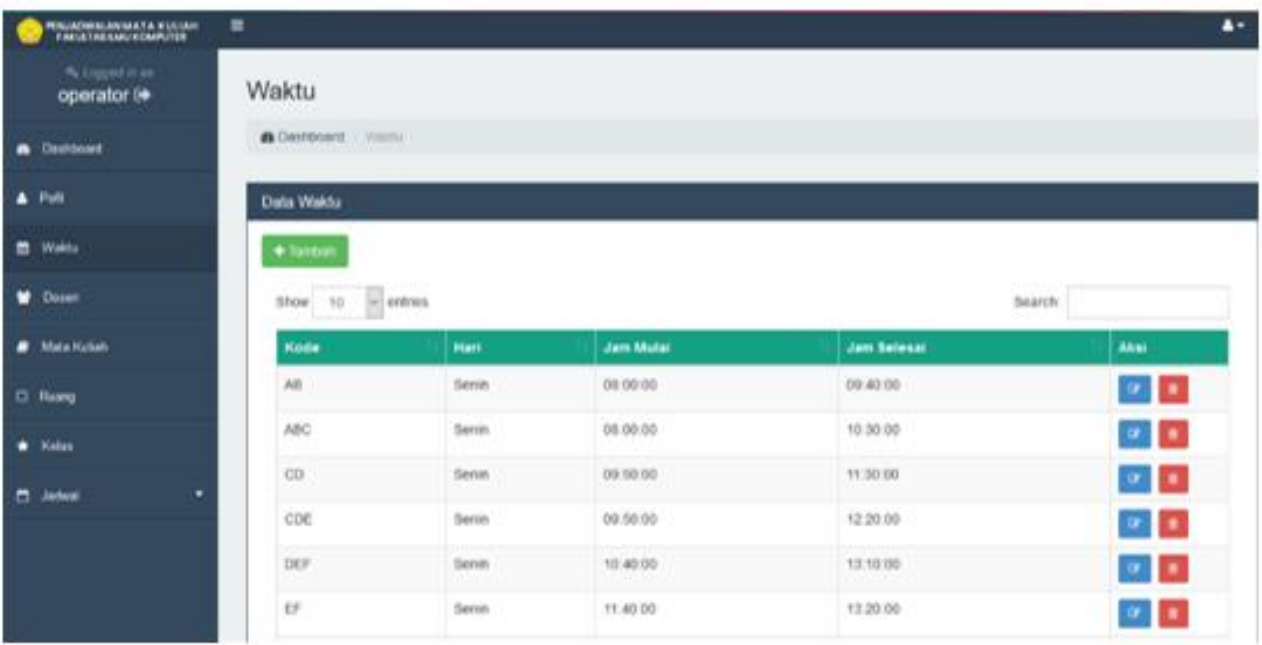

Gambar 4. Halaman Waktu

Perancangan Aplikasi Penjadwalan Mata Kuliah Di Fakultas Ilmu Komputer Universitas Katolik Santo Thomas. 
Gambar 5 berikut adalah tampilan antar muka menu dosen. Form ini memiliki fitur yaitu Tambah data dosen, edit dosen dan hapus dosen.

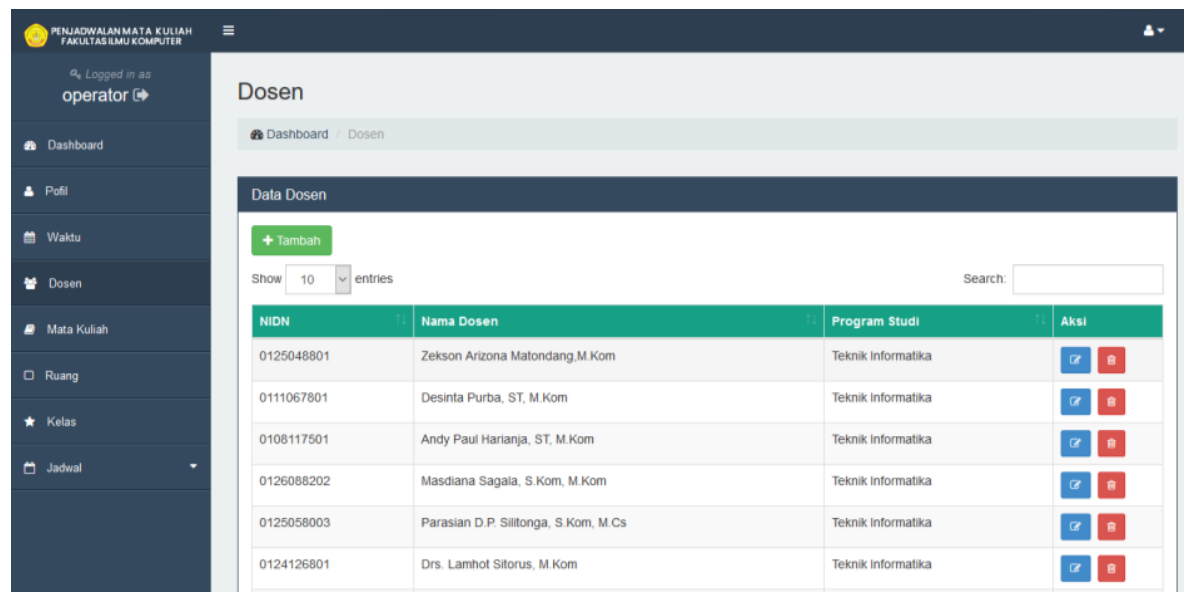

Gambar 5. Halaman Dosen

Gambar 6 berikut adalah tampilan antar muka menu Mata Kuliah. Form ini memiliki fitur yaitu Tambah Kode Mata Kuliah,Nama Mata Kuliah, Jumlah SKS, Semester,Program Studi,Kurikulum dan Jenis Ruang.

\begin{tabular}{|c|c|c|c|c|c|c|c|c|}
\hline 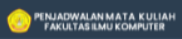 & $\equiv$ & & & & & & & \\
\hline $\begin{array}{l}\text { Q Logped in as } \\
\text { operator } C\end{array}$ & \multicolumn{8}{|c|}{ Mata Kuliah } \\
\hline - Oashbourd & \multicolumn{8}{|c|}{ - Dashboard Mata Kuiah } \\
\hline \& Potit & \multicolumn{8}{|c|}{ Data Mata Kullah } \\
\hline - Waku & \multicolumn{8}{|l|}{+ Tamban } \\
\hline * Dosen & \multicolumn{6}{|c|}{ Show $10 \square$ entries } & \multicolumn{2}{|c|}{ search: } \\
\hline - Mata Kulaht & Kode & Mata Kullah & sks & Semester & Program studi & Kurikulum & Jenis & Aksi \\
\hline \multirow[t]{3}{*}{ O Ruang } & 08120204 & Administrasi Basisdata & 3 & 5 & Sistem intomasi & $\mathrm{mani}$ & Teon & a日 \\
\hline & 08140043 & Akuntansi Dasar & 2 & 2 & Sistem infomasi & knni & Teori & a: \\
\hline & 08120024 & Algorttma dan Struktur Data & 3 & 1 & Sistem intormasi & kni & Teori & a日 \\
\hline \multirow[t]{3}{*}{ Q Jadual } & 08120144 & Analisa Perancangan Sistem Intormasi & 3 & 4 & Sistem intormasi & $\mathrm{kmni}$ & Teori & a. \\
\hline & 08120193 & Auat Sistem Intomasi & 2 & 5 & Sistem informasi & kni & Teori & a \\
\hline & 08120102 & Banasa indonesia & 2 & 4 & Sistem intomasi & knni & Teon & a \\
\hline
\end{tabular}

Gambar 6. Halaman Mata Kuliah

Gambar 7 berikut adalah tampilan antar muka menu Ruang. Form ini memiliki fitur yaitu Tambah Nama Ruang,Kapasitas Ruang,Jenis Ruang.

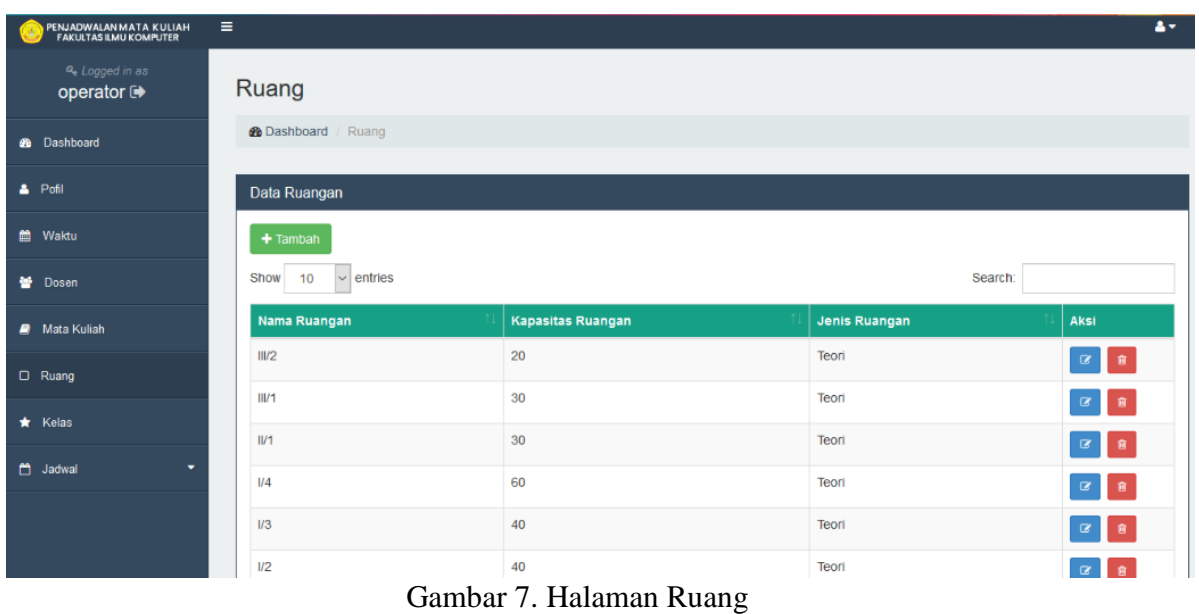

Perancangan Aplikasi Penjadwalan Mata Kuliah Di Fakultas Ilmu Komputer Universitas Katolik Santo Thomas. 
Gambar 8 berikut adalah tampilan antar muka menu Kelas. Form ini memiliki fitur yaitu Tambah data mata kuliah yang akan di generate menjadi jadwal mata kuliah.

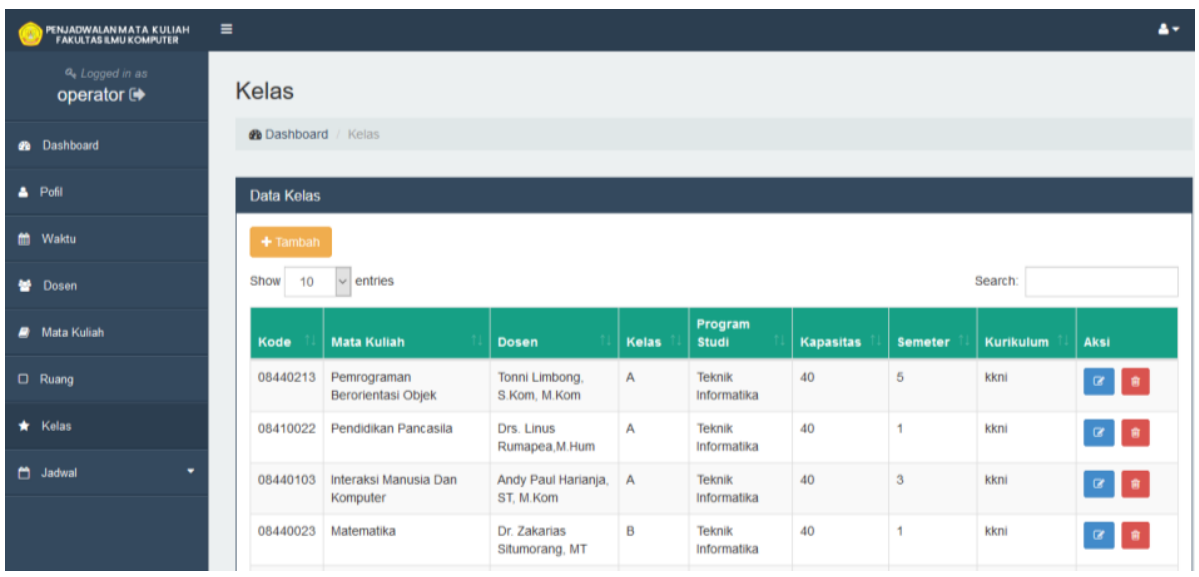

Gambar 8. Halaman Kelas

Gambar 9 berikut adalah proses untuk membuat jadwal mata kuliah, langkah yang harus dilakukan adalah memilih Tahun ajaran setelah memilih tekan tombol Buat Jadwal maka proses pembuatan jadwal akan berjalan.

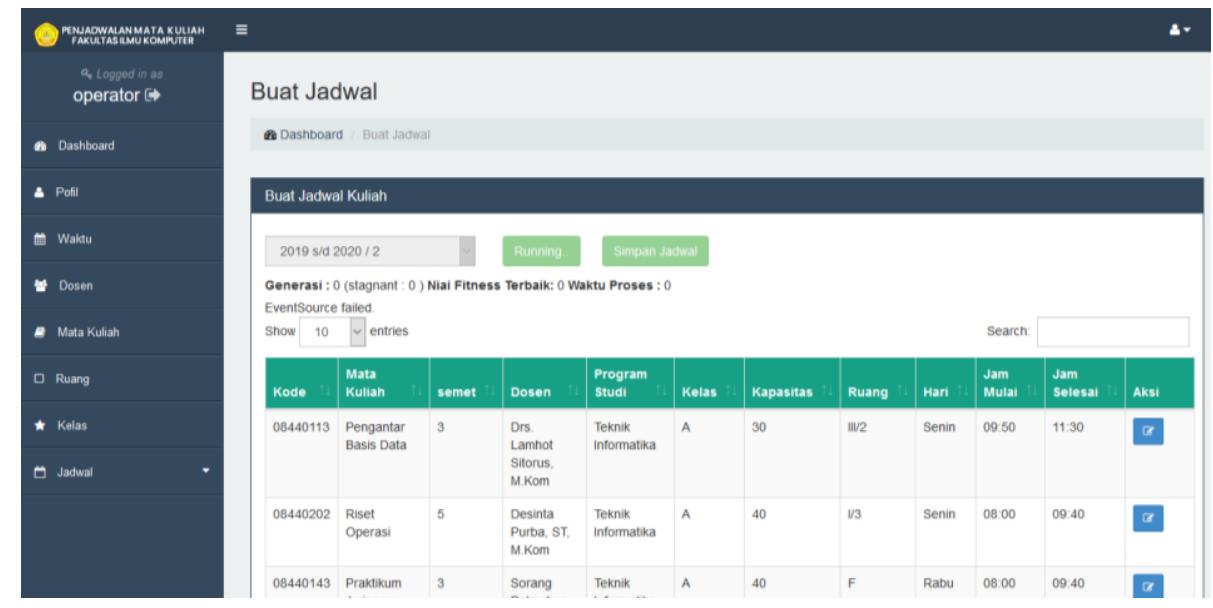

Gambar 9. Halaman Buat Jadwal

Gambar 10 berikut adalah proses untuk melihat jadwal mata kuliah yang sudah di buat, langkah yang harus dilakukan adalah memilih Tahun ajaran setelah itu akan di tampilkan jadwal yang telah di buat.

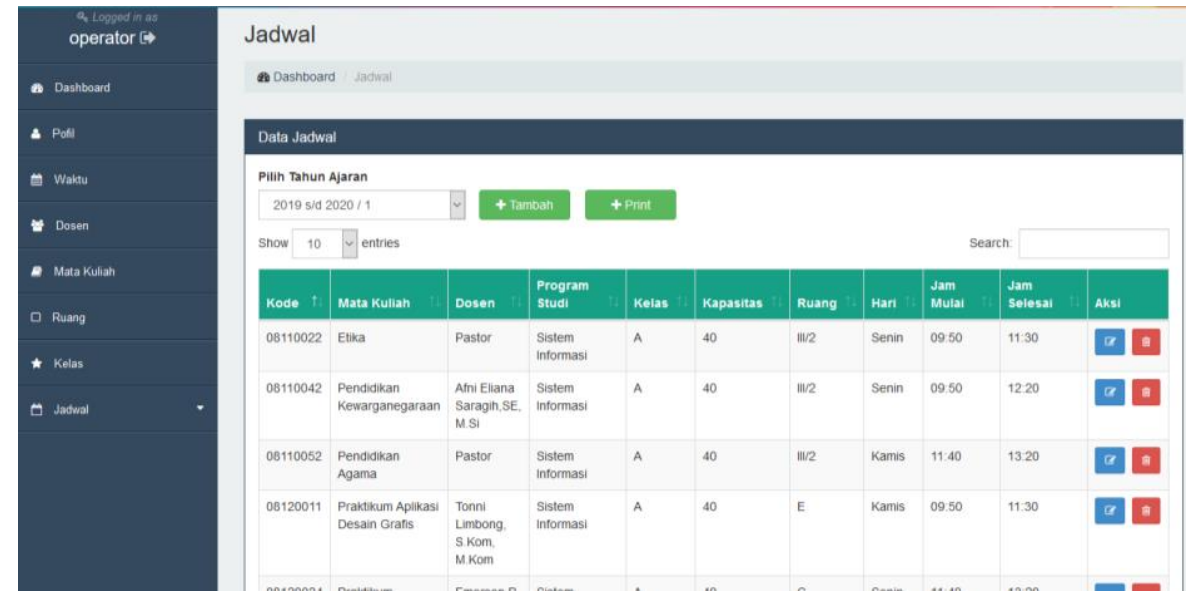

Gambar 10. Halaman Lihat Jadwal

Perancangan Aplikasi Penjadwalan Mata Kuliah Di Fakultas Ilmu Komputer Universitas Katolik Santo Thomas. 
Gambar 11 dan 12 berikut adalah proses untuk mencetak jadwal mata kuliah yang sudah di buat, langkah yang harus dilakukan adalah meng-klik tombol print, disitu kita dapat mencetak jadwal berdasarkan Tahun ajaran dan jadwal berdasarkan dosen pengampu.

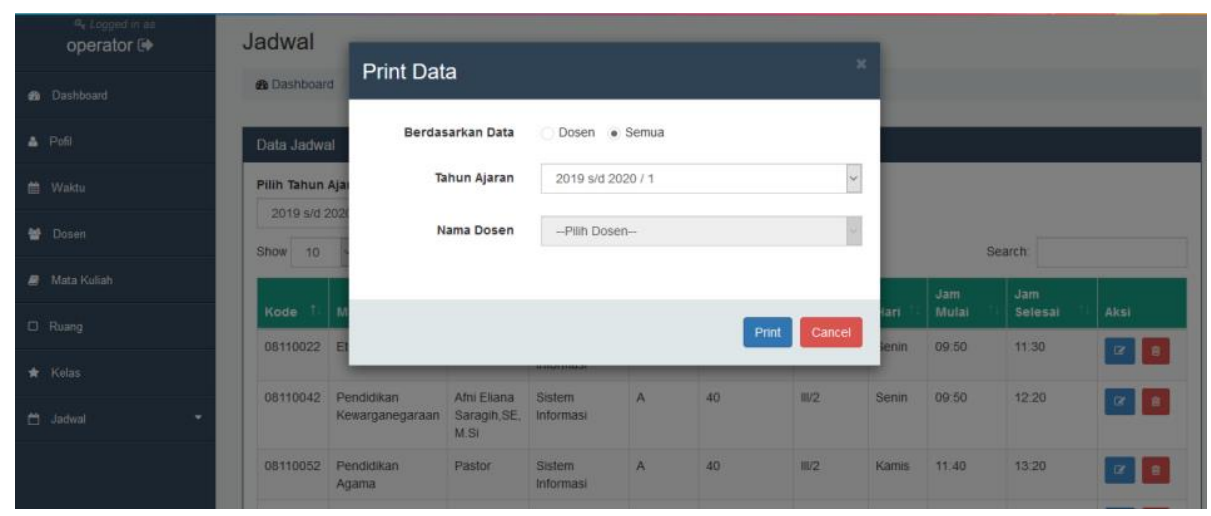

Gambar 11. Cetak Jadwal

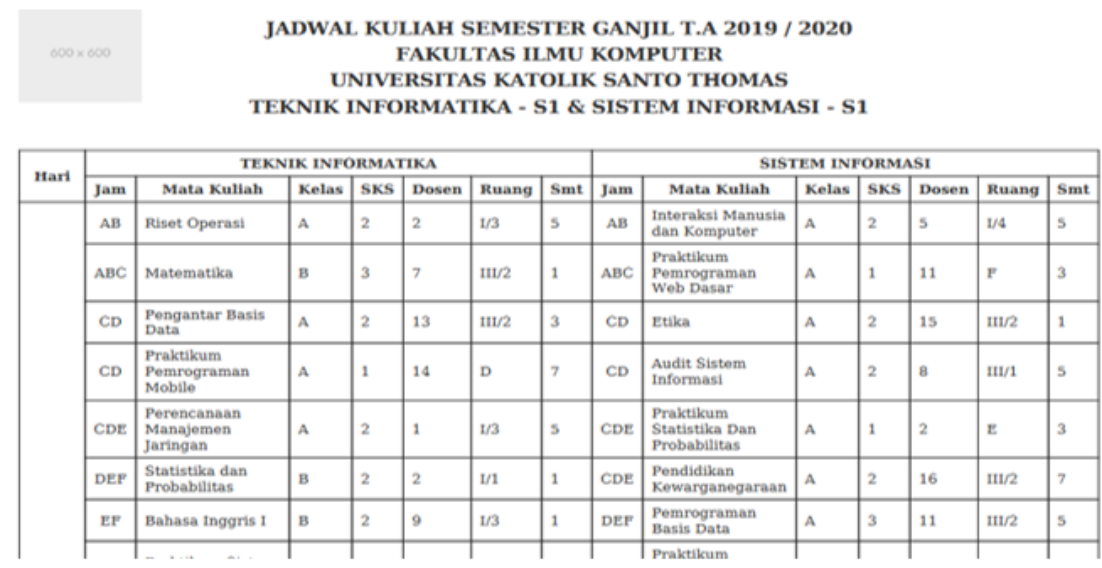

Gambar 12. Hasil Cetak Jadwal

\section{KESIMPULAN}

Berdasarkan hasil pembuatan model penjadwalan dengan menggunakan metode Algoritma Genetika dapat disimpulkan beberapa hal di bawah ini:

1. Dengan adanya sistem penjadwalan ini proses penjadwalan mata kuliah di Fakultas Ilmu Komputer Universitas Katolik Santo Thomas dapat di buat dengan efisien.

2. Dengan adanya sistem penjadwalan ini maka di perolah penjadwalan matakuliah yang optimal pada Fakultas Ilmu Komputer Universitas Katolik Santo Thomas sehingga dapat menimalkan jumlah jadwal yang bentrok.

\section{DAFTAR PUSTAKA}

[1] P. D. P. Silitonga and N. P. Pasaribu, "Optimasi Penjadwalan Mata Kuliah Fakultas Ilmu Komputer Universitas Katolik Santo Thomas Sumatera Utara Dengan Menggunakan Algoritma Genetika," J. Tek. Inform. UNIKA St. Thomas, vol. 1, no. 2, pp. 2548-1916, Dec. 2016, doi: 10.17605/JTI.V1I2.29.

[2] K. Krisnandi and H. Agung, "Implementasi Algortima Genetika Untuk Memprediksi Waktu dan Biaya Pengerjaan Proyek Konstruksi,” J. Ilm. FIFO, vol. 9, no. 2, p. 90, Nov. 2017, doi: 10.22441/fifo.2017.v9i2.001.

[3] S. Samaher and W. Firdaus Mahmudy, "Penerapan Algoritma Genetika Untuk Memaksimalkan Laba Produksi Jilbab," J. Enviromental Eng. Sustain. Technol., vol. 2, no. 1, pp. 6-11, Jul. 2015, doi: 10.21776/ub.jeest.2015.002.01.2.

[4] H. Andy Paul and H. Mei Lestari, "Perancangan Sistem Penjadwalan Perkuliahan dengan Algoritma Genetika Berbasis Web (Studi Kasus : Fakultas Ilmu Komputer Universitas Katolik Santo Thomas),” vol. 2, no. 1, pp. 63-68, 2020.

[5] N. Purwana et al., "Optimalisasi penempatan dosen pembimbing dan penjadwalan seminar tugas akhir menggunakan algoritma genetika," Semin. Nas. Teknol. Inf. dan Komun. 2016 (SENTIKA 2016), vol. 2016, no. Sentika, pp. 18-19, 2016.

Perancangan Aplikasi Penjadwalan Mata Kuliah Di Fakultas Ilmu Komputer Universitas Katolik Santo Thomas.

Oleh : Andy Paul Harianja, Rolas Meiputra Nababan. 
[6] A. P. Harianja, S. Pakpahan, and L. Sitorus, Pedoman Penulisan Skripsi Fakultas Ilmu Komputer Universitas Katolik Santo Thomas Medan, 3rd ed. Medan: Fakultas Ilmu Komputer, UNIKA Santo Thomas, 2017.

[7] Suendri, "Implementasi Diagram UML (Unified Modelling Language) Pada Perancangan Sistem Informasi Remunerasi Dosen Dengan Database Oracle (Studi Kasus: UIN Sumatera Utara Medan)," Algoritm. J. Ilmu Komput. dan Inform., vol. 2, no. 2, p. 1, Jan. 2018, Accessed: Nov. 16, 2020. [Online]. Available: http://www.omg.org.

[8] T. Limbong, "Perancangan Sistem Informasi Kehadiran Mengajar Dosen," Pelita Inform. Inf. dan Inform., 2012. 